\title{
Ultrafast Dynamics in the Metal-to-Ligand Charge Transfer Excited-State Evolution of $\left[\operatorname{Ru}\left(4,4^{\prime} \text {-diphenyl-2,2'-bipyridine }\right)_{3}\right]^{2+}$
}

\author{
Niels H. Damrauer and James K. McCusker* \\ Department of Chemistry, University of California at Berkeley, Berkeley, California 94720-1460
}

Received: August 5, 1999

\begin{abstract}
The transition metal complexes $\left[\mathrm{Ru}(\mathrm{dmb})_{3}\right]^{2+}$ and $\left[\mathrm{Ru}(\mathrm{dpb})_{3}\right]^{2+}$, where $\mathrm{dmb}$ is $4,4^{\prime}$-dimethyl-2,2'-bipyridine and dpb is $4,4^{\prime}$-diphenyl-2,2'-bipyridine, have been studied by femtosecond visible electronic absorption spectroscopy. Spectroelectrochemical measurements in conjunction with nanosecond time-resolved absorption spectroscopy allow for the assignment of various features in the excited-state differential absorption spectra as both ligand-based $\pi^{*} \leftarrow \pi^{*}$ and ligand-to-metal charge transfer (LMCT) in nature. A unique absorptive feature centered at $\sim 530 \mathrm{~nm}$ in $\left[\mathrm{Ru}(\mathrm{dpb})_{3}\right]^{2+}$ was identified as an optical marker for the thermalized (and hence fully intraligand delocalized) excited state. Single wavelength and full spectrum transient absorption data were obtained on both molecules in $\mathrm{CH}_{3} \mathrm{CN}$ solution at room temperature following metal-to-ligand charge transfer (MLCT) excitation at $400 \mathrm{~nm}$. Data on $\left[\mathrm{Ru}(\mathrm{dmb})_{3}\right]^{2+}$ at $532 \mathrm{~nm}$, a region of net excited-state absorption, revealed biphasic decay kinetics $\left(\sim 120\right.$ fs and 5 ps) attributed to a combination of ${ }^{1}$ MLCT $\rightarrow$ ${ }^{3}$ MLCT intersystem crossing and vibrational cooling dynamics. Dynamics for $\left[\mathrm{Ru}(\mathrm{dpb})_{3}\right]^{2+}$ under identical conditions revealed biphasic rise times in the region of the ligand-based $\pi^{*} \leftarrow \pi^{*}$ absorption at $\lambda_{\text {probe }}=532$ $\mathrm{nm}$. Although the origin of the fast component $(\sim 200 \mathrm{fs})$ is not yet clear, the ca. 2 ps rise is assigned to rotation of the peripheral aryl ring and thus corresponds to the time scale for intraligand electron delocalization.
\end{abstract}

\section{Introduction}

Metal polypyridyl complexes, particularly those of ruthenium and osmium, have long served as convenient templates for the study of the photoinduced properties of transition metal complexes. ${ }^{1}$ Whereas considerable efforts have been made to understand such systems with regard to their photoreactivity on nanosecond to microsecond time scales, relatively little is known about the dynamics associated with the formation of these long-lived excited states. The metal-to-ligand charge transfer (MLCT) transition that initiates much of the excitedstate processes exhibited by these compounds can be written as follows

$$
\left[\mathrm{M}^{\mathrm{II}}(\mathrm{L})_{3}\right]^{2+} \stackrel{h v}{\longrightarrow}\left[\mathrm{M}^{\mathrm{III}}(\mathrm{L})_{2}\left(\mathrm{~L}^{-}\right)\right]^{2+}
$$

where photon absorption formally oxidizes the metal center and reduces the ligand. Thus, properties of the ligand which affect the acceptor orbitals can strongly influence the overall energetics of the MLCT transition itself as well as subsequent dynamics of excited-state relaxation. It is in this context that we have studied the ultrafast visible absorption dynamics of two MLCT ions $\left[\mathrm{Ru}(\mathrm{dmb})_{3}\right]^{2+}$ and $\left[\mathrm{Ru}(\mathrm{dpb})_{3}\right]^{2+}$ in $\mathrm{CH}_{3} \mathrm{CN}$, where dmb is $4,4^{\prime}$-dimethyl-2,2'-bipyridine and $\mathrm{dpb}$ is $4,4^{\prime}$-diphenyl-2,2' bipyridine.

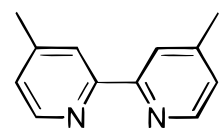

$\mathrm{dmb}$

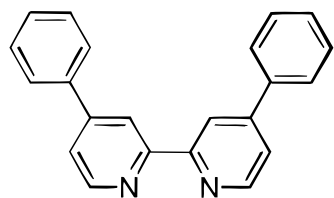

$\mathrm{dpb}$
We have previously reported details of the static and nanosecond time scale photophysical properties of these compounds in $\mathrm{CH}_{3} \mathrm{CN}$ at room temperature. ${ }^{2}$ It was observed that the $\left[\mathrm{Ru}(\mathrm{dpb})_{3}\right]^{2+}$ complex has a substantially smaller rate of nonradiative ${ }^{3}$ MLCT $\rightarrow{ }^{1} \mathrm{~A}_{1}$ relaxation following ${ }^{1} \mathrm{MLCT} \leftarrow$ ${ }^{1} \mathrm{~A}_{1}$ absorption than what is seen for $\left[\mathrm{Ru}(\mathrm{dmb})_{3}\right]^{2+}$. Using a combination of synthetic and spectroscopic methods, ${ }^{2}$ we demonstrated that the drop in nonradiative decay $\left(k_{\mathrm{nr}}\right)$ for $[\mathrm{Ru}-$ $\left.(\mathrm{dpb})_{3}\right]^{2+}$ was linked to a decrease in excited-state geometric distortion relative to the ground state because of extensive conjugation between the bipyridyl fragment and the aryl substituents in the excited state. Theoretical studies of model ligand systems further supported the assignment of a fully conjugated reduced ligand in the excited state. ${ }^{3}$ A similar effect has been described in the context of other $\mathrm{Ru}^{\mathrm{II}}$ and $\mathrm{Cu}^{\mathrm{I}}$ systems, ${ }^{4-8}$ and we refer to it as intraligand electron delocalization.

In the initial discussion of the long-lived excited-state properties of these systems, we also reported a crystal structure of a bis-heteroleptic complex containing the dpb ligand $[\mathrm{Ru}-$ $\left.(\mathrm{dmb})_{2}(\mathrm{dpb})\right]^{2+}$. This structure revealed that the phenyl/pyridyl ring systems of the dpb ligand were not coplanar in the ground state but rather showed a $28^{\circ}$ (av) dihedral angle. An ab initio geometry optimization of the neutral 4-phenylpyridine as a model for the ground-state structure of $\mathrm{dpb}$ supports this, suggesting an even larger dihedral angle of $\theta=44.6^{\circ}$ (MP2/ 6-31G(d)) between the phenyl and pyridyl rings. ${ }^{3}$ These observations suggest that the evolution of the ${ }^{1}$ MLCT FranckCondon state to the long-lived ${ }^{3}$ MLCT state includes rotational dynamics of the phenyl substituents in the $\left[\mathrm{Ru}(\mathrm{dpb})_{3}\right]^{2+}$ complex. In this report, we present visible femtosecond transient absorption data that allow us to observe in real time the evolution of electronic features accompanying ring rotation and thus electron delocalization in this system. 


\section{Experimental Section}

General. All reagents and materials from commercial sources were used as received unless otherwise noted. Solvents were purchased from Fisher. The ligands 4,4'-dimethyl-2,2'-bipyridine $(\mathrm{dmb})$ and 4,4'-diphenyl-2,2'-bipyridine (dpb) were purchased from Aldrich Chemical Co. The metal complexes $\left[\mathrm{Ru}(\mathrm{dmb})_{3}\right]-$ $\left(\mathrm{PF}_{6}\right)_{2}$ and $\left[\mathrm{Ru}(\mathrm{dpb})_{3}\right]\left(\mathrm{PF}_{6}\right)_{2}$, were prepared according to previously published procedures. ${ }^{2}$ Static absorption spectra were collected using a Hewlett-Packard HP8452A diode array spectrophotometer. Nanosecond difference absorption spectra were collected with $\sim 10$ ns time resolution using an optical parametric oscillator-based spectrometer, the details of which are given elsewhere. $^{2}$

UV-Vis Spectroelectrochemistry. Spectroelectrochemical measurements were made within a home-built optical cell (based on a previously published design ${ }^{9}$ ), fitted with a vitreous carbon working electrode, a platinum counter electrode, and a $\mathrm{Ag}$ / $\mathrm{AgNO}_{3}$ reference electrode. Measurements were taken $180^{\circ}$ from the light source with the optical cell mounted within the HP spectrophotometer such that the light beam passes through an $\sim 3 \mathrm{~mm}$ diameter hole in the working electrode. Solutions of the metal complexes were prepared in $0.1 \mathrm{M} \mathrm{TBAPF}_{6} /$ acetonitrile with an optical density of $\sim 1.4$ ( $1 \mathrm{~cm}$ path length) at 460 and $480 \mathrm{~nm}$ for $\left[\mathrm{Ru}(\mathrm{dmb})_{3}\right]^{2+}$ and $\left[\mathrm{Ru}(\mathrm{dpb})_{3}\right]^{2+}$, respectively. Samples were prepared and placed within the optical cell in an argon filled drybox using thoroughly dried and degassed acetonitrile. Measurements were taken outside the drybox so a positive pressure of dry nitrogen was maintained within the cell. ${ }^{10}$

Oxidative Spectra of $\left[R u(d m b)_{3}\right]^{2+}$ and $\left[R u(d p b)_{3}\right]^{2+}$. With the working electrode at $0 \mathrm{~V}$, a blank of the spectrophotometer was made with the light traveling through the cell, working electrode, and sample solution. In this configuration, the groundstate absorption spectrum becomes a baseline from which changes can be observed. The electrode was then placed at a positive potential $100-200 \mathrm{mV}$ beyond the $E_{1 / 2}$ values for the reversible $3+/ 2+$ couples for the respective molecules ${ }^{2}$ and the percent change in current was monitored. The potentials that were used were $+975 \mathrm{mV}$ for $\left[\mathrm{Ru}(\mathrm{dmb})_{3}\right]^{2+}$ and $+1100 \mathrm{mV}$ for $\left[\mathrm{Ru}(\mathrm{dpb})_{3}\right]^{2+}$ vs $\mathrm{Ag} / \mathrm{AgNO}_{3}$. For both molecules, oxidative bulk electrolysis was completely reversible. Spectra acquired at early times (e.g., $5 \mathrm{~min}$ ) are qualitatively equivalent to those taken at later times (e.g., $40 \mathrm{~min}$ ) with the spectral features growing in intensity as the bulk electrolysis approaches completion. Spectra reported herein correspond to $40 \mathrm{~min}$ of electrolysis for $\left[\mathrm{Ru}(\mathrm{dmb})_{3}\right]^{2+}$ and $20 \mathrm{~min}$ for $\left[\mathrm{Ru}(\mathrm{dpb})_{3}\right]^{2+}$.

Reductive Spectra of $\left[R u(d m b)_{3}\right]^{2+}$ and $\left[R u(d p b)_{3}\right]^{2+}$. Following a blank of the spectrophotometer with $0 \mathrm{~V}$ at the working electrode, reductive spectra were collected with the working electrode placed at a potential between the first and second reversible reductive waves. ${ }^{2}$ The potentials that were used were $-1875 \mathrm{mV}$ for $\left[\mathrm{Ru}(\mathrm{dmb})_{3}\right]^{2+}$ and $-1600 \mathrm{mV}$ for $\left[\mathrm{Ru}(\mathrm{dpb})_{3}\right]^{2+}$ vs $\mathrm{Ag} / \mathrm{AgNO}_{3}$. Unfortunately, while cyclic voltametry of these two molecules shows reversible electrochemistry for the ligand reduction, side products of unknown composition are eventually formed over the course of bulk electrolysis. Portions of the spectrum where isosbestic behavior exists in the initial stages of reduction (e.g., $\sim 480 \mathrm{~nm}$ for $\left[\mathrm{Ru}(\mathrm{dpb})_{3}\right]^{2+}$ ) are therefore monitored, with the loss of isosbestic behavior taken as an indication of side product formation. The data presented corresponds to absorption spectra taken while isosbestic points persisted $\left(9 \mathrm{~min}\right.$ for $\left[\mathrm{Ru}(\mathrm{dmb})_{3}\right]^{2+}$ and $10 \mathrm{~min}$ for $\left[\mathrm{Ru}(\mathrm{dpb})_{3}\right]^{2+}$.)

Femtosecond Visible Difference Absorption Kinetics and Full Spectra. Femtosecond electronic absorption data were acquired using a spectrometer based on a regeneratively amplified Ti:sapphire laser system. Samples were photoexcited at $400 \mathrm{~nm}(\sim 120 \mathrm{fs})$ and probed with a white-light continuum generated from $800 \mathrm{~nm}$ light in sapphire.

A commercial Ti:sapphire oscillator (Coherent: Mira 900) pumped by a sealed tube Ar:ion laser (Coherent: Innova 316P) provided $\sim 500 \mathrm{~mW}$ at $76 \mathrm{MHz}$ as the seed for a Nd:YLF pumped Ti:sapphire regenerative amplifier (Positive Light: Spitfire). This system produces $\sim 900 \mu \mathrm{J}$ pulses of $\sim 90 \mathrm{fs}$ light at $800 \mathrm{~nm}$ at a repetition rate of $1 \mathrm{kHz}$. The output is split 90/ 10 with the larger portion being used to generate the frequency doubled $400 \mathrm{~nm}$ pump ( $\sim 120 \mathrm{fs})$ and the smaller portion used to generate the white light continuum probe in the single filament regime by focusing $\sim 2 \mu \mathrm{J}$ into a $1 \mathrm{~mm}$ plate of sapphire. The $400 \mathrm{~nm}$ pump is passed through an optical chopper, directed on a computer controlled translation stage (Aerotech: $3.3 \mathrm{fs} / \mathrm{step}$ time resolution), and softly focused $(\sim 1$ $\mathrm{mm}$ ) into a $1 \mathrm{~mm}$ path length flow cell containing the sample in solution with an optical density of $\sim 0.4$ at $400 \mathrm{~nm}$. The pump polarization is horizontal and $\sim 4 \mu \mathrm{J}$ are used to excite the sample. The sample is flowed using a peristaltic pump to remove a thermal lensing effect due to the pump laser; however, no photoproducts are observed. The $800 \mathrm{~nm}$ light used to generate the white light continuum is polarized at $54.7^{\circ}$ with respect to the pump to remove anisotropy effects. Off-axis parabolic mirrors are used to collimate and focus the white light into the sample at an acute angle $\left(\sim 5^{\circ}\right)$ with respect to the pump. Reflective surfaces are used to minimize the temporal chirp in the white light spectrum: we observe an approximate 3-fold reduction in chirp ( $\sim 300$ fs between 480 and $650 \mathrm{~nm}$ ) using reflective surfaces rather than lenses.

Single wavelength kinetics measurements are made by passing the probe through a $10 \mathrm{~nm}$ band-pass filter of the appropriate wavelength positioned after the sample and then onto an amplified Si photodiode (Thor labs). A reference beam of $800 \mathrm{~nm}$ light (not chopped) is directed onto a matched amplified photodiode. The signal and reference are passed through a differential amplifier and then into a digital lock-in amplifier (Stanford Research: SR810) synchronized to the chopper frequency of $\sim 500 \mathrm{~Hz}$. To increase the dynamic reserve, the reference beam is modulated with a variable neutral density filter to null the differential voltage seen by the lock-in at negative times. ${ }^{11}$ In this way, the lock-in automatically records a change in transmittance as excited-state absorption or bleach transitions are produced by the pump pulse. At the time these measurements were made, we were unable to accurately measure the intensity of the probe light in the absence of the pump $\left(T_{\mathrm{o}}\right)$ necessary for calculation of true $\Delta A$ values because of saturation of the lock-in amplifier. However, the full spectra data reported do represent accurate $\Delta A$ values. The kinetics data presented are an average of six scans where a single scan corresponds to intensity data collected at each of the time points visited by the translation stage in a forward direction averaged with data collected at the same time points in the reverse direction. The lock-in time constant was set at $300 \mathrm{~ms}$.

To collect full spectrum data, the white light probe is coupled into a spectrograph (Spex 270M) and dispersed horizontally (wavelength) on a Princeton Instruments thermoelectrically cooled CCD with a pixel dimension of $512 \times 512$. For a given time position, data is collected for $1 \mathrm{~s}$. Prior to a given scan, $T_{\mathrm{o}}$ is determined at the first negative time point by averaging 10 shots (one second each). This is used for all subsequent times sampled in a scan for the calculation of $\Delta A$. For $\left[\mathrm{Ru}(\mathrm{dpb})_{3}\right]^{2+}$ 


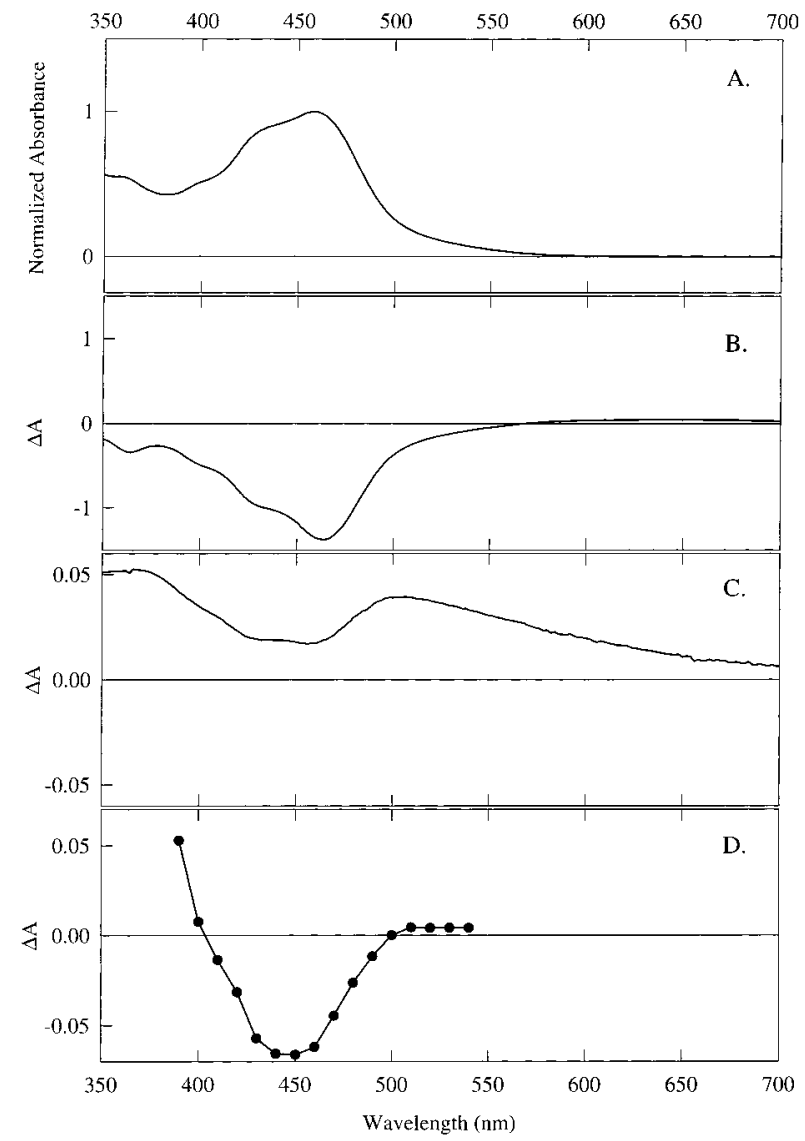

Figure 1. (A) Normalized visible absorption spectrum for $\left[\mathrm{Ru}(\mathrm{dmb})_{3}\right]$ $\left(\mathrm{PF}_{6}\right)_{2}$ in acetonitrile at room temperature. (B) Change in absorbance for $\left[\mathrm{Ru}(\mathrm{dmb})_{3}\right]\left(\mathrm{PF}_{6}\right)_{2}$ in $0.1 \mathrm{M} \mathrm{TBAPF}_{6} /$ acetonitrile following oxidation at $+975 \mathrm{mV}$ (vs $\mathrm{Ag} / \mathrm{AgNO}_{3}$ ) for $40 \mathrm{~min}$. (C) Change in absorbance for $\left[\mathrm{Ru}(\mathrm{dmb})_{3}\right]\left(\mathrm{PF}_{6}\right)_{2}$ in $0.1 \mathrm{M} \mathrm{TBAPF}_{6} /$ acetonitrile following reduction at $-1875 \mathrm{mV}$ (vs $\mathrm{Ag} / \mathrm{AgNO}_{3}$ ) for 9 min. (D) Nanosecond difference absorption spectrum for $\left[\mathrm{Ru}(\mathrm{dmb})_{3}\right]\left(\mathrm{PF}_{6}\right)_{2}$ in acetonitrile.

and $\left[\mathrm{Ru}(\mathrm{dmb})_{3}\right]^{2+}$ the data presented represents a software average of 10 scans and 20 scans, respectively.

Because of the temporal chirp of the white light, two-photon absorption (TPA) cross-correlation measurements were made at each of the wavelengths where single wavelength kinetics were collected in order to determine the zero time $\left(t_{0}\right)$ as well as an instrument response function (IRF) for the measurement. The sample used consisted of 1-methylnaphthalene $\mathrm{e}^{12,13}$ dissolved in acetonitrile ( $\sim$ : 4 by volume) and placed in a $1 \mathrm{~mm}$ static optical cell. placed in the The experiment is then run in the single wavelength kinetics mode. Two scans were adequate to accurately determine $t_{\mathrm{o}}$, and the measured IRFs were approximately Gaussian in profile ${ }^{14}$ with $\sim 220 \mathrm{fs}$ fwhm.

\section{Results and Discussion}

Nanosecond Excited-State Absorption and Spectroelectrochemistry. We have previously used nanosecond transient absorption spectra as a tool for the interpretation of ultrafast dynamics of transition metal complexes, as they reflect excitedstate features once early-time evolution is complete. ${ }^{15}$ The nanosecond absorption difference spectra for $\left[\mathrm{Ru}(\mathrm{dmb})_{3}\right]^{2+}$ and $\left[\mathrm{Ru}(\mathrm{dpb})_{3}\right]^{2+}$ in $\mathrm{CH}_{3} \mathrm{CN}$ at room temperature are shown in the two bottom panels (panel D) of Figures 1 and 2, respectively. The negative (bleach) features occur in the spectral region of the respective ground-state MLCT transitions and therefore largely represent a loss of ground-state absorption. For both molecules, an excited-state absorption is seen in the near

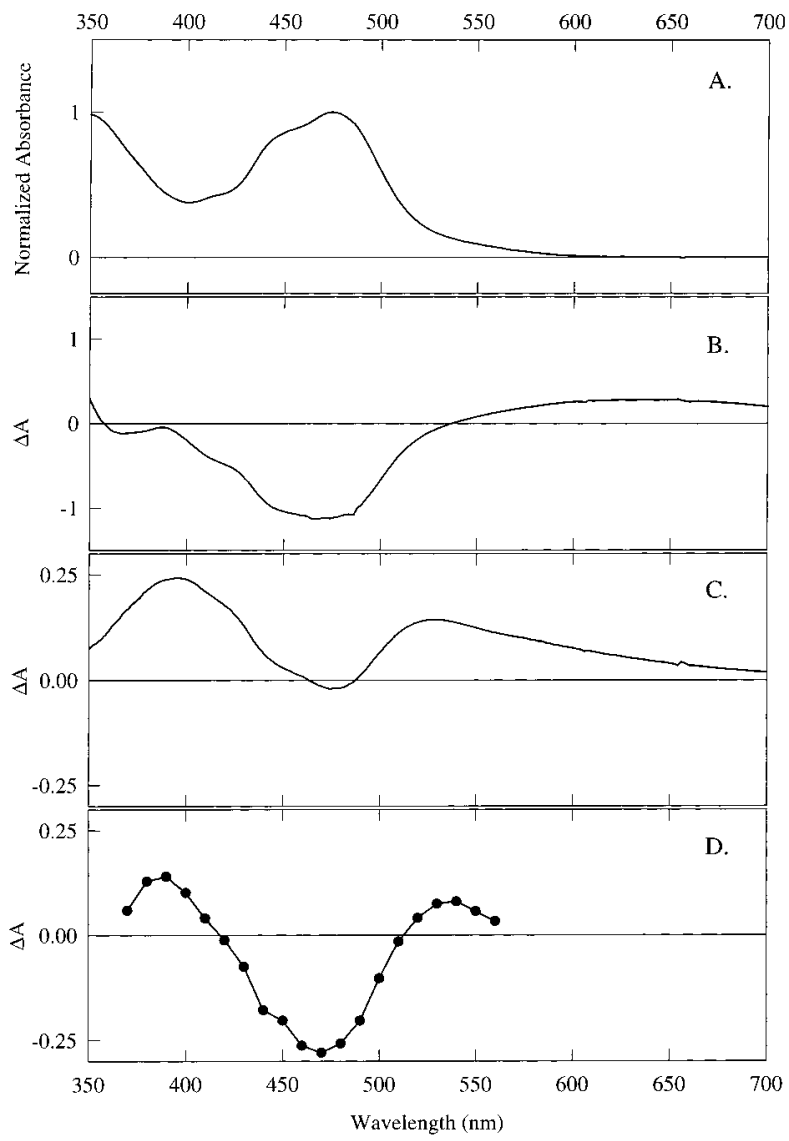

Figure 2. (A) Normalized visible absorption spectrum for $\left[\mathrm{Ru}(\mathrm{dpb})_{3}\right]$ $\left(\mathrm{PF}_{6}\right)_{2}$ in acetonitrile at room temperature. (B) Change in absorbance for $\left[\mathrm{Ru}(\mathrm{dpb})_{3}\right]\left(\mathrm{PF}_{6}\right)_{2}$ in $0.1 \mathrm{M} \mathrm{TBAPF}_{6} /$ acetonitrile following oxidation at $+1100 \mathrm{mV}$ (vs $\mathrm{Ag} / \mathrm{AgNO}_{3}$ ) for $20 \mathrm{~min}$. (C) Change in absorbance for $\left[\mathrm{Ru}(\mathrm{dpb})_{3}\right]\left(\mathrm{PF}_{6}\right)_{2}$ in $0.1 \mathrm{M} \mathrm{TBAPF}_{6} /$ acetonitrile following reduction at $-1600 \mathrm{mV}$ (vs $\mathrm{Ag} / \mathrm{AgNO}_{3}$ ) for $10 \mathrm{~min}$. (D) Nanosecond difference absorption spectrum for $\left[\mathrm{Ru}(\mathrm{dpb})_{3}\right]\left(\mathrm{PF}_{6}\right)_{2}$ in acetonitrile.

ultraviolet $^{16-19}$ as well as somewhat weaker net absorptions further to the red. In $\left[\mathrm{Ru}(\mathrm{dpb})_{3}\right]^{2+}$, this absorption has a substantially larger oscillator strength than the broad and relatively featureless transition seen in the $\left[\mathrm{Ru}(\mathrm{dmb})_{3}\right]^{2+}$ spectrum.

The excited-state difference spectra of charge-transfer complexes are complicated by the simultaneous presence of transitions characteristic of the formally oxidized metal center and its surrounding ligands as well as those of the formally reduced ligand species. We have used spectroelectrochemistry to determine absorption properties of both the $\mathrm{Ru}^{\mathrm{III}}$ oxidized species as well as the singly reduced metal complexes (where the radical anion resides on one of the three ligands) in order to assign features of the excited-state difference spectrum of the longlived ${ }^{3}$ MLCT state. ${ }^{20}$ While we do not expect quantitative agreement, it has been shown by a number of workers that qualitative features can be readily identified. ${ }^{16,21}$ Figure 1A shows a normalized absorption spectrum for $\left[\mathrm{Ru}(\mathrm{dmb})_{3}\right]^{2+}$ and Figure 1B shows the change in absorbance following electrochemical oxidation. The negative feature which peaks at $\sim 460$ $\mathrm{nm}$ corresponds with the loss of the ground-state MLCT transition. Also seen is a broad absorptive transition peaked at $\sim 640 \mathrm{~nm}$. On the basis of its energetic proximity to the emission band in this complex, as well as previous reports in the literature, ${ }^{16,22}$ this transition is assigned as ligand-to-metal charge transfer (LMCT) in nature arising from transitions between neutral ligand orbitals and the formally oxidized metal center. Figure $1 \mathrm{C}$ shows the analogous change in absorbance following 
partial reduction of the original solution. Absorptive transitions are observed in the visible $(\sim 500 \mathrm{~nm})$ and in the near-UV $(\sim$ $380 \mathrm{~nm}$ ), both of which are assigned as $\pi^{*} \leftarrow \pi^{*}$ transitions of the reduced ligand. Using these data, we ascribe the transient absorption observed in the mid-visible to the $\mathrm{dmb}^{-}$chromophore of

the ${ }^{3}$ MLCT excited state and assign it as a ligand-localized $\pi^{*} \leftarrow \pi^{*}$ transition. Absorptions further to the red (not shown in the nanosecond difference spectrum ${ }^{23}$ but observed in the femtosecond difference spectra (vide infra)) are assigned as a convolution of LMCT transition(s) and the low energy shoulder of the reduced ligand $\pi^{*} \leftarrow \pi^{*}$ absorption.

A similar analysis can be carried out for $\left[\mathrm{Ru}(\mathrm{dpb})_{3}\right]^{2+}$. Figure 2A shows a normalized absorption spectrum of the compound in $\mathrm{CH}_{3} \mathrm{CN}$, with Figure $2 \mathrm{~B}$ and $\mathrm{C}$ illustrating the oxidative and reductive spectroelectrochemical data, respectively. Similar to $\left[\mathrm{Ru}(\mathrm{dmb})_{3}\right]^{2+}$, oxidation results in a bleach of the ground-state MLCT absorption along with the formation of a broad lowenergy LMCT absorption ${ }^{16,22}$ centered at $640 \mathrm{~nm}$. In this case, however, the transition is substantially more intense than what is seen for $\left[\mathrm{Ru}(\mathrm{dmb})_{3}\right]^{2+} \cdot{ }^{22,24}$ Upon reduction, two transitions are observed: one in the near-UV $(\sim 400 \mathrm{~nm})$ and one in the mid-visible $(\sim 525 \mathrm{~nm})$, the latter being in good agreement with the previously reported spectrum of the reduced free ligand. ${ }^{2}$ Comparison of these data with the nanosecond difference spectrum (Figure 2D) reveals some obvious correlations. In particular, the strong visible absorption at $532 \mathrm{~nm}$ in the ${ }^{3}$ MLCT difference spectrum is assigned as a $\pi^{*} \leftarrow \pi^{*} \operatorname{transition(s)~of~}$ $\mathrm{dpb}^{-}$. Band(s) further to the red, observed in the femtosecond difference absorption spectra (vide infra), are assigned as primarily LMCT in nature with some contribution from the lowenergy shoulder of the $\pi^{*} \leftarrow \pi^{*} \operatorname{transition}(\mathrm{s})$ of $\mathrm{dpb}^{-}$. The oscillator strength of the absorption at $532 \mathrm{~nm}$ is significantly larger than what is observed for the $\mathrm{dmb}^{-}$chromophore: this presumably reflects the larger transition dipole associated with the extended $\pi$ system of the planar $\mathrm{dpb}^{-}$species. $^{2,3} \mathrm{We}$ therefore view the $\sim 532 \mathrm{~nm}$ visible transient absorption in [Ru$\left.(\mathrm{dpb})_{3}\right]^{2+}$ as a good spectroscopic tag for monitoring intraligand excited-state delocalization in this complex. Thus, we can expect that a time-dependent increase in the intensity of this transition will reflect the time scale for ring rotation concomitant with the evolution of intraligand electron delocalization in the excited state.

Femtosecond Electronic Absorption Spectroscopy of [Ru$\left.(\mathbf{d m b})_{3}\right]^{2+}$. The expected absence of large-amplitude structural dynamics in the excited-state evolution of the ${ }^{3}$ MLCT state of $\left[\mathrm{Ru}(\mathrm{dmb})_{3}\right]^{2+}$ makes this molecule a useful control for understanding fast dynamics in $\left[\mathrm{Ru}(\mathrm{dpb})_{3}\right]^{2+}$. Figure 3 shows normalized kinetic traces measured at $480 \mathrm{~nm}$ (top), $532 \mathrm{~nm}$ (middle), and $650 \mathrm{~nm}$ (bottom) following $\sim 120 \mathrm{fs}$ excitation of a $\mathrm{CH}_{3} \mathrm{CN}$ solution of $\left[\mathrm{Ru}(\mathrm{dmb})_{3}\right]^{2+}$ at $400 \mathrm{~nm}$. These wavelengths represent three distinct regions of the excited-state spectrum. The $480 \mathrm{~nm}$ transient bleach does not reveal dynamics after the pulse-width limited rise. The intensity of the differential absorption following the initial rise is observed to be constant out to $\Delta t=40 \mathrm{ps}$ and therefore reflects the change in absorbance measured in the nanosecond time-resolved experiment. These results are consistent with our previous report on the excitedstate spectroscopy of $\left[\mathrm{Ru}(\mathrm{bpy})_{3}\right]^{2+},{ }^{15}$ in which time evolution in the redder portions of this bleach, i.e., $480 \mathrm{~nm}$, was shown to be complete within the first $100 \mathrm{fs}$. Transient absorption data were collected at $532 \mathrm{~nm}$ (Figure 3, middle) to interrogate a portion of the spectrum characteristic of the $\mathrm{dmb}^{-}$chromophore formed by the charge-transfer transition. In contrast to the data

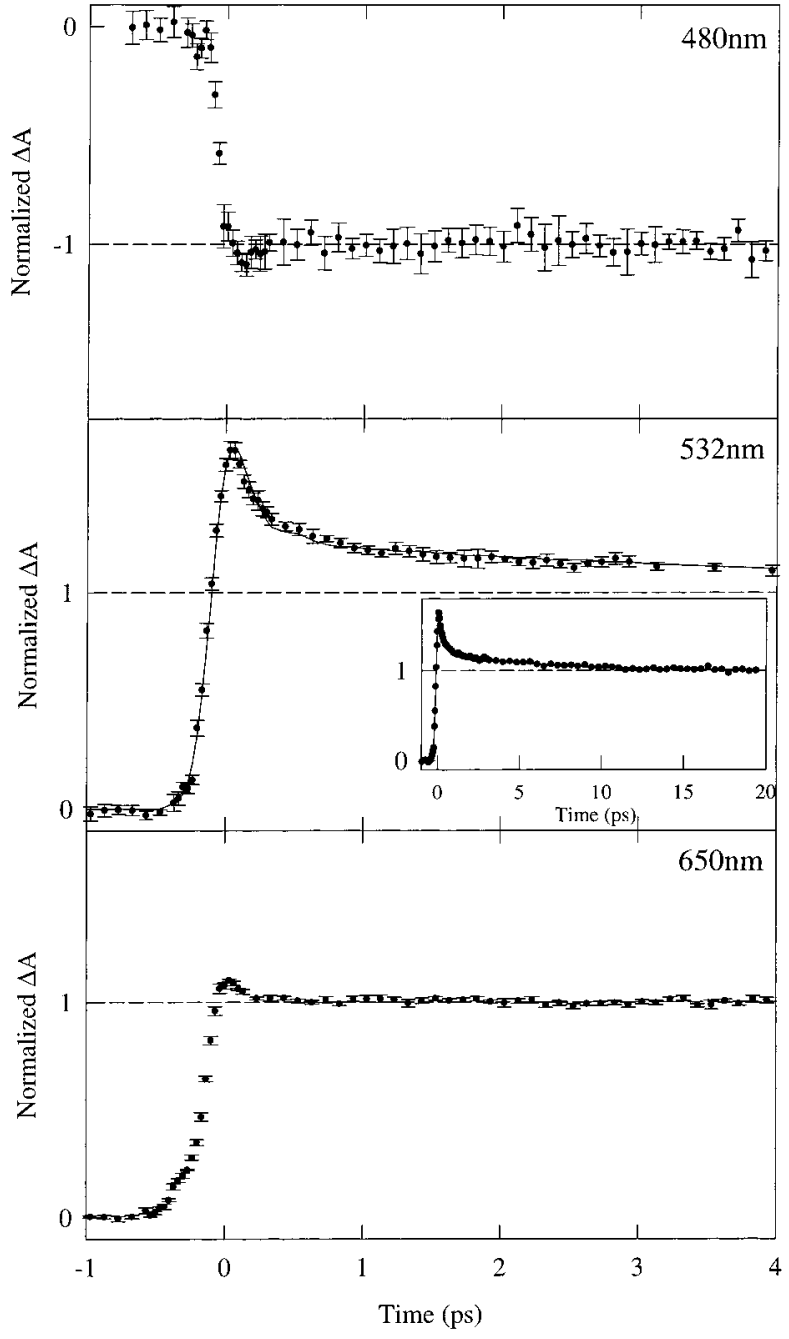

Figure 3. Normalized pump-probe difference absorption kinetics measurements for $\left[\mathrm{Ru}(\mathrm{dmb})_{3}\right]\left(\mathrm{PF}_{6}\right)_{2}$ in acetonitrile resulting from 400 $\mathrm{nm}(\sim 120 \mathrm{fs})$ excitation. Probe wavelengths are indicated on the figure. The inset for $\lambda_{\text {probe }}=532 \mathrm{~nm}$ shows data acquired at longer delay times. The solid line included for $\lambda_{\text {probe }}=532 \mathrm{~nm}$ is the fit of the data with a Gaussian instrument response function and a biexponential function with a constant offset at long times. See text for details.

obtained at $480 \mathrm{~nm}$, we observe decay kinetics which are not complete until $\sim 15$ ps (see inset). Following deconvolution, the kinetics can be fit with a double exponential decay function (with a constant offset corresponding to the differential absorption of the long-lived thermalized ${ }^{3}$ MLCT state), consisting of a fast component ( $\tau=120 \pm 40 \mathrm{fs}$ ) as well as a slower decay ( $\tau=5 \pm 0.5 \mathrm{ps}$ ). It should be noted that femtosecond transient absorption data previously collected on $\left[\mathrm{Ru}(\mathrm{bpy})_{3}\right]^{2+}$ at $\lambda_{\text {probe }}$ $=510 \mathrm{~nm}$ following a $30 \mathrm{fs}$ excitation pulse at $480 \mathrm{~nm}$ showed no dynamics after 200 fs. ${ }^{15}$ However, when pumping at 400 $\mathrm{nm}$ with the present apparatus, slower decay dynamics analogous to those shown in Figure 3 for $\left[\mathrm{Ru}(\mathrm{dmb})_{3}\right]^{2+}$ are also observed for $\left[\mathrm{Ru}(\mathrm{bpy})_{3}\right]^{2+}$ at $532 \mathrm{~nm}$. We therefore believe that the $\sim 5$ ps component in the excited-state relaxation of $\left[\mathrm{Ru}(\mathrm{dmb})_{3}\right]^{2+}$ reflects vibrational cooling dynamics in the ${ }^{3}$ MLCT excited state. The fast decay component is difficult to interpret with our $\sim 120$ fs time resolution. However, on the basis of our previous shorter time scale measurements on $\left[\mathrm{Ru}(\mathrm{bpy})_{3}\right]^{2+}$, it is reasonable to infer that these fast dynamics reflect contributions from the ${ }^{1}$ MLCT $\rightarrow{ }^{3}$ MLCT surface crossing which may include spectral shifting and fast vibrational relaxation occurring on the time scale of the excitation pulse. 


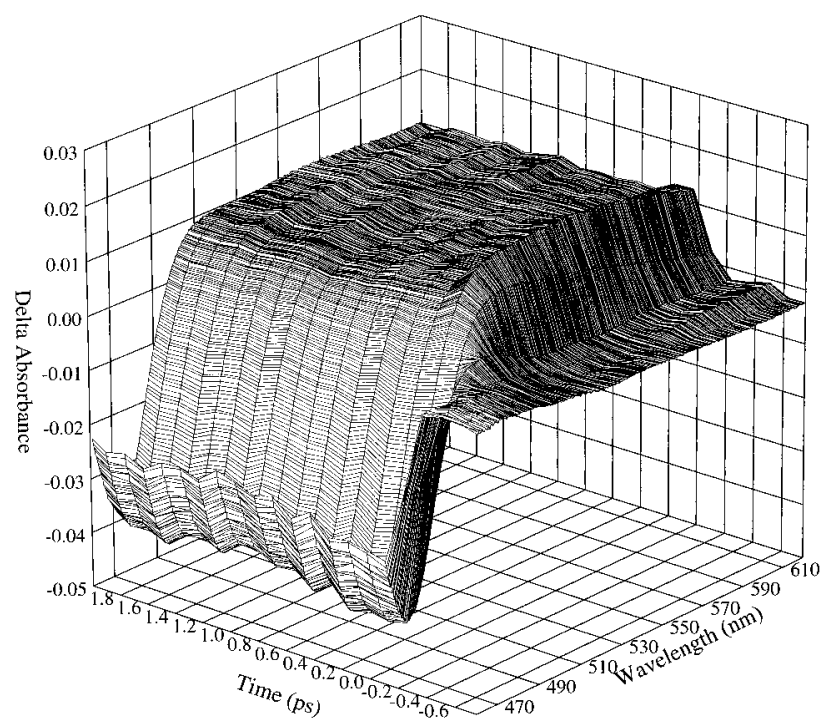

Figure 4. Pump-probe difference absorption spectra for $\left[\mathrm{Ru}(\mathrm{dmb})_{3}\right]$ $\left(\mathrm{PF}_{6}\right)_{2}$ in acetonitrile as a function of time following $\sim 120 \mathrm{fs}$ excitation at $400 \mathrm{~nm}$.

The transient absorption kinetics collected at $650 \mathrm{~nm}$ (Figure 3 , bottom), shows no time evolution after the pulse width limited rise and a weak fast decay component. Again, fast decay dynamics are difficult to interpret but are expected to echo changes in the electronic structure during the ${ }^{1} \mathrm{MLCT} \rightarrow{ }^{3} \mathrm{MLCT}$ intersystem crossing process. The absence of slower decay dynamics was initially surprising in comparison to the very noticeable $\sim 5$ ps decay at $532 \mathrm{~nm}$. Presumably, this reflects differences in the nature of the excited-state transitions being probed $^{25}$ and/or an increase in the rate of vibrational cooling as the excited state(s) are probed further to the red. ${ }^{26,27}$ Variable wavelength excitation studies currently underway will help to clarify these issues.

Full spectral data in the region $470-610 \mathrm{~nm}$ are shown in Figure 4. These measurements were made to ensure that decay dynamics observed for the single wavelengths discussed above were not a result of band shifting on these time scales. The bleach at shorter wavelengths is observed to form rapidly with no indication of evolution after excitation. ${ }^{28}$ Qualitatively similar decay dynamics are observed across the featureless transient absorption from $\sim 500-610 \mathrm{~nm}$, confirming that there is no significant spectral shifting influencing the kinetics described above.

Femtosecond Electronic Absorption Spectroscopy of [Ru$\left.(\mathbf{d p b})_{3}\right]^{2+}$. Figure 5 shows normalized traces collected at 480 nm (top), $532 \mathrm{~nm}$ (middle), and $650 \mathrm{~nm}$ (bottom) following excitation of a $\mathrm{CH}_{3} \mathrm{CN}$ solution of $\left[\mathrm{Ru}(\mathrm{dpb})_{3}\right]^{2+}$ at $400 \mathrm{~nm}$. The data collected at $480 \mathrm{~nm}$ show a rapid, pulse width limited formation of the bleach. As was noted above for $\left[\mathrm{Ru}(\mathrm{dmb})_{3}\right]^{2+}$, no subsequent dynamics are observed. The most striking feature in the excited-state dynamics of this compound is revealed by the data at $532 \mathrm{~nm}$ (Figure 5, middle). As discussed above, this spectral region is diagnostic of the highly delocalized reduced ligand excited state for $\left[\mathrm{Ru}(\mathrm{dpb})_{3}\right]^{2+}$. These data can be fit with a fast $200 \pm 50$ fs component and a slower $2.0 \pm 0.5$ ps component, both of which reflect absorption increases, evolving to a constant background that corresponds to the thermalized ${ }^{3}$ MLCT state. The kinetics in the immediate region of the 532 $\mathrm{nm}$ band are the only data collected for these two molecules where an increase in excited-state oscillator strength is observed. This is consistent with our model for the dynamics of ring rotation (and, correspondingly, intraligand electron delocaliza-

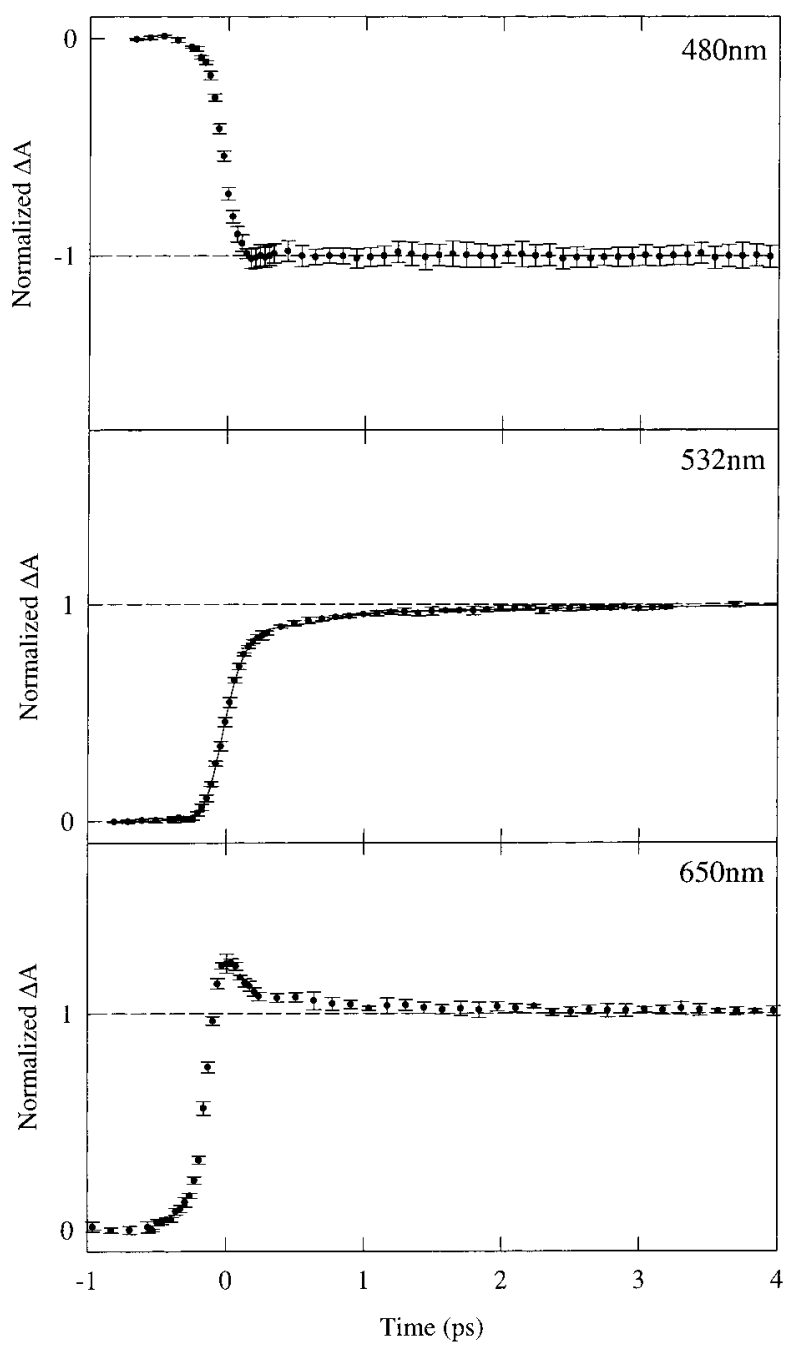

Figure 5. Normalized pump-probe difference absorption kinetics measurements for $\left[\mathrm{Ru}(\mathrm{dpb})_{3}\right]\left(\mathrm{PF}_{6}\right)_{2}$ in acetonitrile resulting from 400 $\mathrm{nm}(\sim 120 \mathrm{fs})$ excitation. Probe wavelengths are indicated on the figure. The solid line included for $\lambda_{\text {probe }}=532 \mathrm{~nm}$ is the fit of the data with a Gaussian instrument response function and a biexponential function with a constant offset at long times. See text for details.

tion), whereby the absorption band rises until reduced-ligand delocalization is complete. We, therefore, ascribe the slow component to the large amplitude motion of the peripheral aryl rings expected to accompany excited-state thermalization in this system. It is important to note the rapid $\sim 2$ ps thermalization of the ligand-localized $(\mathrm{dpb})^{-}$excited-state in $\left[\mathrm{Ru}(\mathrm{dpb})_{3}\right]^{2+}$ compared to the slower $(\sim 5 \mathrm{ps})$ time scale for the analogous excited state in $\left[\mathrm{Ru}(\mathrm{dmb})_{3}\right]^{2+}$. We interpret this as an indication that ring-rotation may be a facile means of dissipating excess vibrational energy. It is interesting to note, along these lines, that the lifetime for the slow rise at $532 \mathrm{~nm}$ is the same to within experimental error as the slow decay observed at $650 \mathrm{~nm}$ (Figure 5 , bottom) The data at this wavelength reveal biphasic kinetics: a fast, instrument-limited decay component followed by a subtle, slower decay on the order of 2 ps. This slow decay is tentatively assigned as vibrational cooling where the mechanism for this process may be coupled to the rotation of the aryl substituents. At present it is difficult to interpret the fast component, but may reflect a combination of ${ }^{1} \mathrm{MLCT} \rightarrow{ }^{3} \mathrm{MLCT}$ intersystem crossing and partial rotation of the aryl substituents. ${ }^{29}$ Again, variable excitation wavelength studies and variable solvent studies currently underway should help to clarify these issues. 


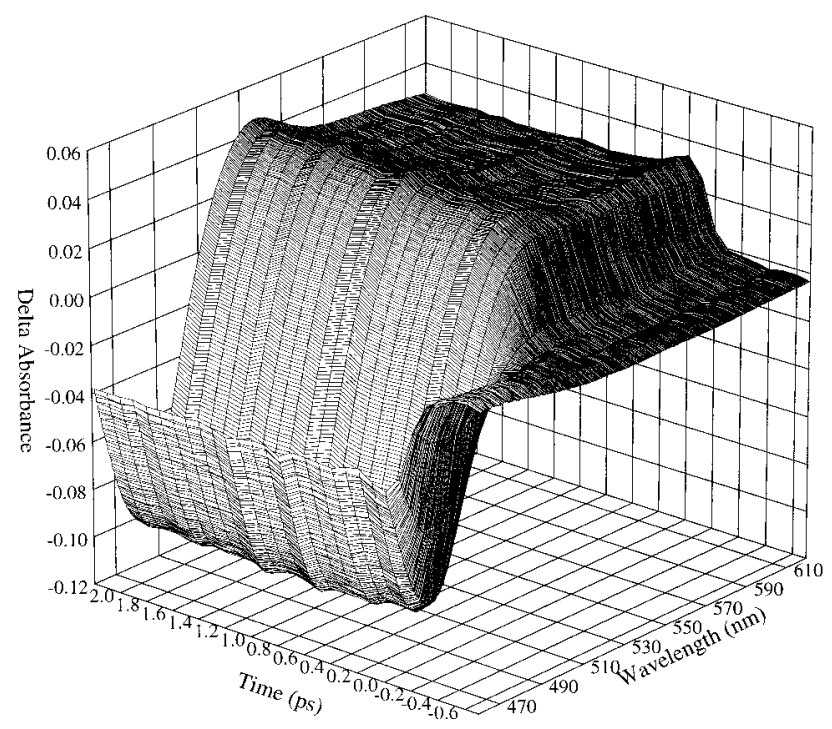

Figure 6. Pump-probe difference absorption spectra for $\left[\mathrm{Ru}(\mathrm{dpb})_{3}\right]-$ $\left(\mathrm{PF}_{6}\right)_{2}$ in acetonitrile as a function of time following $\sim 120 \mathrm{fs}$ excitation at $400 \mathrm{~nm}$.

Full spectral data for $\left[\mathrm{Ru}(\mathrm{dpb})_{3}\right]^{2+}$ in the region $470-610$ $\mathrm{nm}$ are shown in Figure 6. As was the case for $\left[\mathrm{Ru}(\mathrm{dmb})_{3}\right]^{2+}$, these measurements were taken to ensure that single wavelength dynamics discussed above were not a result of spectral shifting on these time scales. The bleach at shorter wavelengths is observed to form rapidly with no indication of dynamics after excitation. The shape of the absorption spectrum for $\lambda>500$ $\mathrm{nm}$ reflects an overlap of the two bands anticipated from the spectroelectrochemical measurement with sharper $\pi^{*} \leftarrow \pi^{*}$ transition(s) of the $\mathrm{dpb}^{-}$chromophore at $\sim 530 \mathrm{~nm}$ and a broader LMCT band to the red. It is clear from the time evolution of these spectra that the $530 \mathrm{~nm} \pi^{*} \leftarrow \pi^{*}$ band exhibits an increase in oscillator strength while the redder LMCT band undergoes a subtle decay at longer times. The important point to make is that the qualitative shape of the absorption band is seen very early in the evolution. ${ }^{28}$ Although slow rise kinetics are still occurring, no significant band shifting is observed. This result is interesting, in that a shift in the $\pi^{*} \leftarrow \pi^{*}$ absorption might be expected given that the degree of $\pi$ conjugation is dynamically increasing. We note, however, that the slow rise component at $532 \mathrm{~nm}$ represents a relatively small fraction of the overall differential absorption (i.e., the absorption change for the ${ }^{3}$ MLCT state). This suggests that the $\sim 530 \mathrm{~nm}$ band is allowed with good oscillator strength in the Franck-Condon state even before complete conjugation has occurred. This is consistent with our previously reported calculations ${ }^{3}$ and ground-state absorption spectrum $^{2}$ for this compound. The dynamic ring rotation therefore appears to increase the transition probability of the $\pi^{*} \leftarrow \pi^{*}$ absorption without significantly perturbing its energy.

\section{Concluding Comments}

In this paper we have presented results from an initial examination of the ultrafast dynamics of arylated $\mathrm{Ru}^{\mathrm{II}}$ polypyridyl complexes. Previous work from our lab suggested that large amplitude molecular motion should be a key component in the excited-state evolution of $\left[\mathrm{Ru}(\mathrm{dpb})_{3}\right]^{2+}$. The femtosecond electronic absorption measurements described herein have demonstrated that those dynamics can indeed be observed and time resolved. Given the intimate connection between electron delocalization and nuclear motion in the excited state of this system, these spectroscopic probes are paramount to directly observing the change in the degree of electron delocalization in real time. In addition, we have begun to identify the time scales for vibrational relaxation dynamics in these complexes. Additional studies of vibrational cooling dynamics, the physical process(es) responsible for the $\sim 100-300$ fs transients that are observed, as well as the influence of solvent and solvation dynamics, are currently underway.

Acknowledgment. This research was supported by the U.S. Department of Energy, Office of Energy Research, Office of Basic Energy Sciences, Division of Chemical Sciences (Grant No. DE-FG03-96ER14665) and the Alfred P. Sloan Foundation.

\section{References and Notes}

(1) Juris, A.; Balzani, V.; Barigelletti, F.; Campagna, S.; Belser, P.; Von Zelewsky, A. Coord. Chem. Rev. 1988, 84, 85 and references therein

(2) Damrauer, N. H.; Boussie, T. R.; Devenney, M.; McCusker, J. K. J. Am. Chem. Soc. 1997, 119, 8253.

(3) Damrauer, N. H.; Weldon, B. T.; McCusker, J. K. J. Phys. Chem. A 1998, 102, 3382 .

(4) Phifer, C. C.; McMillan, D. R. Inorg. Chem. 1986, 25, 1329.

(5) Boyde, S.; Strouse, G. F.; Jones, W. E.; Meyer, T. J. J. Am. Chem. Soc. 1990, 112, 7395 .

(6) Strouse, G. F.; Schoonover, J. R.; Duesing, R.; Boyde, S.; Jones, W. E.; Meyer, T. J. Inorg. Chem. 1995, 34, 473.

(7) Hammarstrom, L.; Barigelletti, F.; Flamigni, L.; Indelli, M. T. Armaroli, N.; Calogero, G.; Guardigli, M.; Sour, A.; Collin, J. P.; Sauvage, J. P. J. Phys. Chem. A 1997, 101, 9061.

(8) Feliz, M. R.; Rodriguez-Nieto, F.; Ruiz, G.; Wolcan, E. J. Photochem. Photobiol. A: Chem. 1998, 117, 185.

(9) Kirchofoff, J. R. Curr. Sep. 1997, 16, 11

(10) This is only important for spectra taken with the electrode at reducing potentials but was done for all measurements nonetheless.

(11) Klimov, V. I.; McBranch, D. W. Opt. Lett. 1998, 23, 278.

(12) Bingemann, D.; Ernsting, N. K. J. Chem. Phys. 1995, 102, 2691.

(13) Dick, B.; Gonska, H.; Hohlneicher, G. Ber. Bunsen-Ges. Phys. Chem. 1981, 85, 746 .

(14) TPA measurements at redder wavelengths such as $650 \mathrm{~nm}$ showed a longer time constant offset having an amplitude of as much as $25 \%$ of the TPA signal. This is believed to be due either to photoproducts formed in the 1-methylnaphthalene and/or longer lived transient absorptions of the parent compound.

(15) Damrauer, N. H.; Cerullo, G.; Yeh, A.; Boussie, T. R.; Shank, C. V.; McCusker, J. K. Science 1997, 275, 54.

(16) Braterman, P. S.; Song, J.-I.; Peacock, R. D. Spectrochim. Acta 1992, 48, 899.

(17) Braterman, P. S.; Song, J.-I.; Peacock, R. D. Inorg. Chem. 1992, 31,555 .

(18) Mahon, C.; Reynolds, W. L. Inorg. Chem. 1967, 6, 1927.

(19) Creutz, C.; Chou, M.; Netzel, T. L.; Okumura, M.; Sutin, N. J. Am. Chem. Soc. 1980, 102, 1309.

(20) The extent to which this is a valid means of estimating excitedstate transitions depends on the energetic consequences of simultaneously having $\mathrm{Ru}^{\mathrm{III}}$ and a reduced ligand species in the $\mathrm{CT}$ excited state. LMCT transitions from the reduced ligand site will be absent in the reductive spectra; however, these are expected to occur in the bleach region. For $\pi^{*}$ $\leftarrow \pi^{*}$ transitions of the reduced ligand, the +2 (rather than +3 ) oxidation state of the metal is expected to represent only a minor change to the energy of the transition through slight differences in the degree of $\pi$ back bonding. For LMCT transitions coupling neutral ligands to the oxidized $\mathrm{Ru}^{\mathrm{III}}$ metal center, the absence of a reduced ligand site is also expected to represent only a small energetic perturbation through inductive effects.

(21) Curtright, A. E.; McCusker, J. K. J. Phys. Chem. A 1999, 103, 7032.

(22) Nazeeruddin, M. K.; Zakeeruddin, S. M.; Kalyanasundaram, K. J. Phys. Chem. 1993, 97, 9607.

(23) The cutoff at $550 \mathrm{~nm}$ for the nanosecond difference absorption spectrum is experimentally imposed because of the onset of emission on these time scales at longer wavelengths.

(24) In addition to the arguments of Nazeeruddin et al., the increase in intensity for this LMCT transition is consistent with the increase in the oscillator strength of the ground-state MLCT absorption between [Ru$\left.(\mathrm{dmb})_{3}\right]^{2+}$ and $\left[\mathrm{Ru}(\mathrm{dpb})_{3}\right]^{2+}$ (cf. refs 2 and 3 ).

(25) As discussed, the transient absorption interrogated at $650 \mathrm{~nm}$ is at least in part LMCT $\left(\mathrm{Ru}^{\mathrm{III}} \leftarrow(\mathrm{dmb} \pi)\right)$ in nature. This implies that the neutral 
ligand participating in the transition is not the ligand involved in the initial MLCT absorption of $400 \mathrm{~nm}$ light. In the limit of weak coupling between excited states in this molecule, it is reasonable to expect that there will be an attenuation of vibrational relaxation that is necessary in the excitedstate probed by the $650 \mathrm{~nm}$ absorption

(26) Harris, A. L.; Brown, J. K.; Harris, C. B. Annu. Rev. Phys. Chem. 1988, 39,341
(27) Kliner, D. A. V.; Alfano, J. C.; Barbara, P. F. J. Chem. Phys. 1993, 98,5375 .

(28) The apparent spectral shift in the initial evolution of the transient full spectral data is due to the $\sim 300 \mathrm{fs}$ temporal chirp $(480-650 \mathrm{~nm})$ within the white light probe (see Experimental Section).

(29) Elich, K.; Kitazawa, M.; Okada, T.; Wortmann, R. J. Phys. Chem. A 1997, 101, 2010. 